\title{
Bortezomib, carfilzomib and ixazomib do not mediate relevant transporter-based drug-drug interactions
}

\author{
JANNICK CLEMENS $^{1}$, LUKAS WELTI ${ }^{1}$, JULIA SCHÄFER ${ }^{1}$, ANJA SECKINGER ${ }^{2}$, \\ JÜRGEN BURHENNE ${ }^{1}$, DIRK THEILE ${ }^{1}$ and JOHANNA WEISS ${ }^{1}$ \\ ${ }^{1}$ Department of Clinical Pharmacology and Pharmacoepidemiology; ${ }^{2}$ Department of Internal Medicine V, \\ Oncology, Hematology and Rheumatology, University Hospital Heidelberg, D-69120 Heidelberg, Germany
}

Received December 29, 2016; Accepted March 9, 2017

DOI: $10.3892 / \mathrm{ol} .2017 .6560$

\begin{abstract}
In order to optimize the clinical application of an increasing number of proteasome inhibitors, investigations into the differences between their respective pharmacodynamic and pharmacokinetic profiles, including their ability to act as a perpetrator in drug-drug interactions, are warranted. Therefore, in the present in vitro study, it was investigated whether bortezomib, carfilzomib and ixazomib are able to alter the expression, and/or the activity, of specific drug transporters generally relevant for pharmacokinetic drug-drug interactions. Through induction experiments, the current study demonstrated that the aforementioned three proteasome inhibitors do not induce mRNA expression of the transporter genes ATP binding cassette $(A B C) B 1, C 1, C 2$ and $G 2$ in the LS180 cell line, which was used as a model for systemic induction. By contrast, in certain myeloma cell lines, ixazomib provoked minor alterations in individual transporter gene expression. None of the proteasome inhibitors tested relevantly inhibited drug transporters within the range of physiological plasma concentrations. Taken together, transporter-based drug-drug interactions are unlikely to be a primary concern in the clinical application of the tested compounds.
\end{abstract}

\section{Introduction}

A decade ago, bortezomib became the first member of the novel chemotherapeutic class of proteasome inhibitors to receive clinical approval (1). Originally developed for the study of proteasome physiology, proteasome inhibitors soon demonstrated significant antineoplastic activity (2) that, starting with bortezomib, was successfully applied in the treatment of

Correspondence to: Professor Johanna Weiss, Department of Clinical Pharmacology and Pharmacoepidemiology, University Hospital Heidelberg, 410 Im Neuenheimer Feld, D-69120 Heidelberg, Germany

E-mail: johanna.weiss@med.uni-heidelberg.de

Key words: bortezomib, carfilzomib, ixazomib, proteasome inhibitors, drug transporter, drug-drug interaction multiple myeloma (3). Subsequently, bortezomib has become an almost indispensable part of the gold standard therapy regimen, significantly improving the treatment outcomes of affected patients (4). However, its clinical applicability is considerably impeded by dose-limiting toxicity (5) and by primary or secondary drug-resistance $(6,7)$. As acquired drug resistance can be mediated by enhanced efflux transporter expression $(8,9)$, it is essential to determine whether anti-myeloma drugs are transported by certain proteins. It has previously been demonstrated that bortezomib is a substrate of the well-known ATP-binding cassette (ABC) transporter $\mathrm{P}$-glycoprotein (P-gp); however, the clinical relevance of this finding remains unclear (10). Furthermore, antineoplastic drugs may induce the expression of similar transporter genes in respective target tissues or cells eventually leading to iatrogenic drug resistance $(8,9)$. Consequently, investigations into the inducing properties of proteasome inhibitors are warranted.

In 2012, the epoxyketone carfilzomib became the second proteasome inhibitor to be approved by the Food and Drug Administration for the treatment of relapsed and refractory multiple myeloma (11). Inducing irreversible proteasome inhibition, carfilzomib not only demonstrates greater preclinical antitumor activity (12), but it is also effective in cell lines already resistant to bortezomib (13). The boronic acid ixazomib is another reversible second-generation proteasome inhibitor that appears to exhibit sufficient activity in bortezomib-resistant myeloma cells, despite structural similarities (14). It has become the first orally bioavailable proteasome inhibitor to be approved for the treatment of recurrent multiple myeloma in the USA (15). In addition to the aspect of drug resistance at a cellular level, it is important to understand the merits and limitations of certain proteasome inhibitors in a given clinical setting characterized by combination chemotherapy or the co-administration of drugs against co-morbidities. Extensive research, therefore, concentrates on the potential differences of proteasome inhibitors in pharmacodynamics, pharmacokinetics and vulnerability to drug-drug interactions (16). Such drug-drug interactions may modulate the systemic availability/exposure of other chemotherapeutics that are typically part of the complex therapy regimen for patients with myeloma $(17,18)$, or that may be used in combination with proteasome inhibitors in the future due to proven synergistic 
effects $(19,20)$. Transporter-based pharmacokinetic drug-drug interactions typically comprise direct inhibition of drug transporters or alterations of their gene expression. In the present study, the inhibitory and induction potentials of bortezomib, carfilzomib and ixazomib on various drug transporters known to relevantly affect systemic pharmacokinetics, and thus the efficacy and safety of pharmacotherapies, were evaluated (21). Furthermore, the effect of these compounds on the expression levels of crucial drug transporters was investigated (1) in a cell model used for assessing inducing properties (LS180 cells) assessing possible drug-drug interactions and (2) in myeloma cell lines, where induction could contribute to iatrogenic treatment failure. The findings indicate that proteasome inhibitors neither relevantly inhibit nor induce drug transporters, suggesting that bortezomib, carfilzomib and ixazomib do not provoke transporter-mediated pharmacokinetic drug-drug interactions. Furthermore, transporter expression remains unchanged in myeloma cell lines upon exposure to proteasome inhibitors, indicating cellular adaptation mechanisms to be of minor relevance. Together, the 'negative results' presented in this study suggest that proteasome inhibitors do not affect drug transporter expression at certain physiological barriers, including the intestine; therefore, proteasome inhibitors are devoid of transporter-based drug-drug interactions.

\section{Materials and methods}

Materials. Bortezomib was purchased from Absource Diagnostics GmbH (Munich, Germany); carfilzomib and ixazomib were purchased from Sequoia Research Products, Ltd. (Pangbourne, UK). The GenElute ${ }^{\mathrm{TM}}$ Mammalian Total RNA Miniprep kit, fumitremorgin C (FTC), doxorubicin, rifampicin, verapamil hydrochloride, all cell culture media [RPMI-1640, Iscove's modified Dulbecco's media (IMDM), Dulbecco's modified Eagle's medium (DMEM)] and supplements were purchased from Sigma-Aldrich (Merck KGaA, Darmstadt, Germany). Fetal calf serum (FCS) was purchased from Biochrom, Ltd. (Cambridge, UK) and geneticin (G418) was supplied by PAA Laboratories (GE Healthcare Life Sciences, Chalfont, UK). Calcein acetoxymethylester (calcein-AM) was obtained from Invitrogen (Thermo Fisher Scientific, Inc., Waltham, MA, USA), and 8-fluorescein-cAMP (8-FcA) from BIOLOG Life Science Institute (Bremen, Germany) and pheophorbide A (PhA) from Frontier Scientific, Ltd. (Carnforth, UK). The RevertAid ${ }^{\mathrm{TM}}$ H Minus First Strand cDNA Synthesis kit from Fermentas (Thermo Fisher Scientific, Inc., Pittsburgh, PA, USA) and the Absolute QPCR SYBR $^{\circledR}$ Green mix was obtained from ABgene (Thermo Fisher Scientific, Inc.). The Cytotoxicity Detection kit was from Roche Applied Science (Mannheim, Germany). Primers were synthesized by Eurofins MWG Operon (Ebersberg, Germany).

Cell lines. The myeloma cell lines used (Karpas-620, L363, OPM-2, EJM, KMM-1, LP-1, RPMI-8226 and U266) were purchased from the German Collection of Microorganisms and Cell Cultures GmbH (Braunschweig, Germany). With the exception of EJM and LP-1 cells, which were cultured in IMDM, all myeloma cell lines were cultured in RPMI-1640 medium. The media were each supplemented with $10 \%$ FCS, $2 \mathrm{mM}$ glutamine, $100 \mathrm{U} / \mathrm{ml}$ penicillin and $100 \mu \mathrm{g} / \mathrm{ml}$ streptomycin sulfate. Cells were cultured at $37^{\circ} \mathrm{C}, 5 \% \mathrm{CO}_{2}$ and $100 \%$ humidity.

The LS180 human colon adenocarcinoma cell line (American Type Culture Collection, Manassas, USA) is one model frequently used for investigating pregnane-X-receptor (PXR) and aryl hydrocarbon receptor mediated induction (22-24), and was used as an induction model in the present study. LS180 cells were cultured under standard cell culture conditions at $37^{\circ} \mathrm{C}, 5 \% \mathrm{CO}_{2}$ and $100 \%$ humidity in DMEM supplemented with $10 \%$ FCS, $2 \mathrm{mM}$ glutamine, $100 \mathrm{U} / \mathrm{ml}$ penicillin, $100 \mu \mathrm{g} / \mathrm{ml}$ streptomycin sulfate and $0.1 \mathrm{mM}$ nonessential amino acids.

Possible inhibitory effects on the human organic anion transporting polypeptides [OATPs, also termed solute carriers of organic anions (SLCOs)] were studied in HEK-293 cells overexpressing SLCO1B1 (HEK-OATP1B1) or SLCOIB3 (HEK-OATP1B3) $(25,26)$. The cell line transfected with the empty control vector was used as a control (HEK-293-VC G418). These cell lines were provided by Dr D. Keppler (German Cancer Research Centre, Heidelberg, Germany) and cultured in DMEM supplemented with 10\% FCS, 2 mM glutamine, $100 \mathrm{U} / \mathrm{ml}$ penicillin, $100 \mu \mathrm{g} / \mathrm{ml}$ streptomycin sulfate, and $800 \mu \mathrm{g} / \mathrm{ml} \mathrm{G} 418$ at $37^{\circ} \mathrm{C}, 5 \% \mathrm{CO}_{2}$ and $100 \%$ humidity.

The ability of the proteasome inhibitors to inhibit breast cancer resistance protein (BCRP) was investigated in MDCKII-BCRP (overexpressing BCRP/ABCG2) cells (27) in comparison with the parental MDCKII cell line. These cells lines were provided by Dr A. H. Schinkel (The Netherlands Cancer Institute, Amsterdam, Netherlands) and cultured in DMEM supplemented with $10 \%$ FCS, 2 mM glutamine, $100 \mathrm{U} / \mathrm{ml}$ penicillin and $100 \mu \mathrm{g} / \mathrm{ml}$ streptomycin sulfate. Cells were cultured at $37^{\circ} \mathrm{C}, 5 \% \mathrm{CO}_{2}$ and $100 \%$ humidity.

The P-gp inhibition assay was performed using the P388 murine monocytic leukemia cell line and the corresponding doxorubicin-resistant P388/dx cells overexpressing mdrla/lb, which are an ideal model for testing P-gp inhibition (28). These two cell lines were provided by Dr D. Ballinari (Pharmacia \& Upjohn, Milano, Italy). The RPMI-1640 culture medium for these cells was supplemented with $10 \%$ FCS, 2 mM glutamine, $100 \mathrm{U} / \mathrm{ml}$ penicillin, $100 \mu \mathrm{g} / \mathrm{ml}$ streptomycin sulfate and $100 \mu \mathrm{M}$ 2-mercaptoethanol. Additionally, doxorubicin $(0.43 \mu \mathrm{M})$ was added to the medium of the P388/dx cells in order to maintain P-gp overexpression; this was discontinued one day prior to each assay. Cells were cultured at $37^{\circ} \mathrm{C}, 5 \%$ $\mathrm{CO}_{2}$ and $100 \%$ humidity.

Growth inhibition assays. To exclude any profound antiproliferative effects of the proteasome inhibitors on LS180 and myeloma cells during the induction assay, growth inhibition assays were conducted to define the maximum concentration ensuring $\sim 80 \%$ cell survival $\left(\mathrm{IC}_{20}\right)$. For the adherent LS180 cells, growth inhibition was quantified following $48 \mathrm{~h}$ of incubation at standard cell culture conditions via crystal violet staining of the surviving cells, as previously described (29). For the myeloma cells, an MTT assay was used to assess growth inhibition following $48 \mathrm{~h}$ of incubation at standard cell culture conditions, as described previously (29). Each experiment was performed in quadruplicate with $\mathrm{n}=8$ wells for each concentration $(0.005,0.01,0.05,0.1,0.5,1,5,10,50$ and $100 \mu \mathrm{M})$. Sigmoid concentration-response curves and $\mathrm{IC}_{20}$ values were 
calculated using GraphPad Prism software (version 6.02; GraphPad Software Inc., La Jolla, CA, USA).

Induction assay. For the induction assays, the cells were treated with bortezomib, carfilzomib, ixazomib, $20 \mu \mathrm{M}$ rifampicin (positive control) or culture medium only (negative control) for 4 days at standard cell culture conditions. All incubation solutions were adjusted to $0.02 \%$ dimethyl sulfoxide. Myeloma cells were exposed to proteasome inhibitor concentrations representing the $\mathrm{IC}_{20}$ value in the corresponding cell line (bortezomib, 1-5 nM; carfilzomib, 1-20 nM; ixazomib, 2-70 nM). LS180 cells were treated with four distinct concentrations (bortezomib, 0.1-5 nM; carfilzomib, 0.5-10 nM; ixazomib, $1-50 \mathrm{nM}$ ), whereas the maximum concentration applied corresponded to the $\mathrm{IC}_{20}$ of proliferation inhibition in this cell line (bortezomib, $7.6 \mathrm{nM}$; carfilzomib, $13 \mathrm{nM}$; ixazomib, $62 \mathrm{nM}$ ). All incubations were conducted at least in quadruplicate. Following harvesting by centrifugation $\left(1,000 \mathrm{x} \mathrm{g}, 5 \mathrm{~min}, 4^{\circ} \mathrm{C}\right)$, the cell pellets were subjected to RNA extraction using the GenElute $^{\mathrm{TM}}$ Mammalian Total RNA Miniprep kit.

Quantification of mRNA expression using reverse transcription-quantitative polymerase chain reaction (RT-qPCR). The purity and concentration of the isolated RNA were determined spectrophotometrically. Using the RevertAid ${ }^{\mathrm{TM}}$ H Minus First Strand cDNA Synthesis kit, cDNA was synthesized according to the manufacturer's protocol. The mRNA expression of $A B C B 1$ (coding for $\mathrm{P}-\mathrm{gp}$ ), $A B C C 1$ [coding for multidrug resistance-associated protein 1 (MRP1)], $A B C C 2$ (coding for MRP2) and $A B C G 2$ (coding for BCRP) was quantified using qPCR with the LightCycler ${ }^{\circledR} 480$ (Roche Applied Science). From each biological sample, one technical PCR duplicate was prepared; prior to PCR, amplification was performed in $20 \mu \mathrm{l}$ total volume containing $5 \mu 1$ 1:10 diluted cDNA, $0.15 \mu \mathrm{M}$ of each primer and $1 \mathrm{X}$ Absolute QPCR SYBR ${ }^{\circledR}$ Green mix for 40 cycles. Primer sequences and thermocycling conditions are listed in Table I.

The most stable housekeeping genes for the treatment of each cell line were identified using geNorm (version 3.4; Centre for Medical Genetics, Ghent, Belgium) (30) and used for normalization. GAPDH was the most stable in LS180, KMM-1, RPMI-8226 and U266 cells under bortezomib treatment, in LS180 cells and LP-1 cells under carfilzomib treatment, and in LP1 cells under ixazomib treatment. $\beta 2$-microglobulin was most stable in EJM cells and OPM-2 cells under bortezomib treatment, in L363 cells under carfilzomib treatment and in Karpas-620, L363, and OPM-2 cells under ixazomib treatment. Hypoxanthine-phosphoribosyl transferase 1 was most stable in Karpas-620, L363 and LP-1 cells under bortezomib treatment, in OPM-2 cells under carfilzomib treatment and in RPMI-8226 cells under ixazomib treatment. The 60S human acidic ribosomal protein P1 was most stable in EJM cells under carfilzomib treatment. Ribosomal protein L13 was most stable in Karpas-620 cells, KMM-1 cells and RPMI-8266 cells under carfilzomib treatment. Glucuronidase- $\beta$ was most stable in U266 cells under carfilzomib treatment, and in LS180 cells, EJM cells, KMM-1 cells and U266 cells under ixazomib treatment.

Data were evaluated using calibrator-normalized relative quantification with efficiency correction using LightCycler ${ }^{\circledR}$
480 software (version 1.5; Roche Applied Science), which calculates the relative amount of the target gene and the reference gene based on the crossing points (Cp) and the underlying calibration curve. The results are expressed as the target/reference ratio divided by the target/reference ratio of the calibrator and are, therefore, corrected for sample inhomogeneities and variance caused by detection. Whenever mRNA expression was below the detection limit ( $\mathrm{Cp}$ value $>35)$, the respective cell line was excluded from further analysis. The degree of induction/repression was then calculated by the mean mRNA expression ratio between the incubated samples and the respective medium control. A threshold of a 1.5 -fold change in mRNA expression normalized to the respective negative control was defined, i.e. normalized mRNA levels $>150 \%$ or $<67 \%$ compared with the control, as induction or repression, respectively. Statistical analysis was performed for these values only.

Drug transporter inhibition assays. The potential inhibitory effects of bortezomib, carfilzomib and ixazomib on the activity of various drug transporters were evaluated and compared between model cell lines overexpressing $A B C B 1$, $A B C G 2, S L C O 1 B 1$ or $S L C O 1 B 3$ in relation to the respective parental cell line. With the use of fluorescent substrates, three drug transporter inhibition assays were performed, as previously described and validated $(22,31,32)$. All experiments were conducted at least in triplicate.

In brief, for the P-gp inhibition assay, P388 and P388/dx cells were pre-incubated with the proteasome inhibitors ( $\leq 10 \mu \mathrm{M}$; each concentration was evaluated in octuplicate) for 15 min at $37^{\circ} \mathrm{C}$ in Hepes buffered Hank's balanced salt solution (HHBSS). Following pre-incubation, calcein-AM was added at a final concentration of $1 \mu \mathrm{M}$ and the cells were further incubated for $30 \mathrm{~min}$ at $37^{\circ} \mathrm{C}$. Following washing twice with ice-cold HHBSS, the cells were lysed in $1 \%$ Triton X-100 for $15 \mathrm{~min}$ at $37^{\circ} \mathrm{C}$ and calcein fluorescence was measured using a Fluoroskan Ascent ${ }^{\mathrm{TM}}$ fluorometer (Thermo Fisher Scientific, Inc.) with $485 \mathrm{~nm}$ excitation and $535 \mathrm{~nm}$ emission filters. The effect in the parental cell line P388 was used to determine whether the effects observed could be attributed to P-gp inhibition. The P-gp inhibitor verapamil served as the positive control.

For the BCRP inhibition assay, MDCKII and MDCKII-BCRP cells were incubated for $30 \mathrm{~min}$ at $37^{\circ} \mathrm{C}$ in RPMI-1640 with $2 \%$ FCS containing $1 \mu \mathrm{M}$ pheophorbide A. Following washing, cells were incubated for $60 \mathrm{~min}$ at $37^{\circ} \mathrm{C}$ with medium containing the proteasome inhibitors at 0.05 , $0.1,0.5,1,5,10,50$ or $100 \mu \mathrm{M}$ Following washing, intracellular fluorescence was analyzed using a $\mathrm{BD}^{\mathrm{TM}}$ LSR II flow cytometer (BD Biosciences, Franklin Lakes, NJ, USA) with a $633 \mathrm{~nm}$ helium/neon laser and a $660 \mathrm{~nm}$ bandpass filter. In each sample, 30,000 cells were counted. To quantify the effects of the proteasome inhibitors, the ratio between the median fluorescence with the inhibitor and without the inhibitor during the efflux period was calculated and normalized to the effect observed in the parental cell line. The selective BCRP inhibitor FTC served as the positive control.

For the OATP inhibition assays, HEK-OATP1B1, HEK-OATP1B3 and HEK-293-VC G418 cells were incubated in PBS with 2\% FCS containing $2.5 \mu \mathrm{M} 8$-FcA with or without 
Table I. Primer sequences and thermocycler conditions used in reverse transcription-quantitative polymerase chain reaction.

\begin{tabular}{|c|c|c|}
\hline Gene & Primers & Thermocycler conditions \\
\hline \multicolumn{3}{|c|}{$\beta 2-\mathrm{mg}$} \\
\hline $\mathrm{F}$ & 5'CCAGCAGAGAATGGAAAGTC3' & \multirow[t]{2}{*}{$15 \mathrm{~s}, 95^{\circ} \mathrm{C} ; 30 \mathrm{~s}, 61^{\circ} \mathrm{C} ; 30 \mathrm{~s}, 72^{\circ} \mathrm{C}$} \\
\hline $\mathrm{R}$ & 5'CATGTCTCGATCCCACTTAAC3' & \\
\hline \multicolumn{3}{|l|}{ GU } \\
\hline $\mathrm{F}$ & 5'TTCAACAGGATCCACCTCTG3' & \multirow[t]{2}{*}{$15 \mathrm{~s}, 95^{\circ} \mathrm{C} ; 30 \mathrm{~s}, 61^{\circ} \mathrm{C} ; 30 \mathrm{~s}, 72^{\circ} \mathrm{C}$} \\
\hline $\mathrm{R}$ & 5'AGCACTCTCGTCGGTGACTG3' & \\
\hline \multicolumn{3}{|c|}{ G6PDH } \\
\hline $\mathrm{F}$ & 5'ATCGACCACTACCTGGGCAA3' & \multirow[t]{2}{*}{$15 \mathrm{~s}, 95^{\circ} \mathrm{C} ; 30 \mathrm{~s}, 61^{\circ} \mathrm{C} ; 30 \mathrm{~s}, 72^{\circ} \mathrm{C}$} \\
\hline $\mathrm{R}$ & 5'TTCTGCATCACGTCCCGGA3' & \\
\hline \multicolumn{3}{|l|}{ HPRT } \\
\hline $\mathrm{F}$ & 5'CTGGCGTCGTGATTAGTG3' & \multirow[t]{2}{*}{$15 \mathrm{~s}, 95^{\circ} \mathrm{C} ; 30 \mathrm{~s}, 61^{\circ} \mathrm{C} ; 30 \mathrm{~s}, 72^{\circ} \mathrm{C}$} \\
\hline $\mathrm{R}$ & 5'CACACAGAGGGCTACAATG3' & \\
\hline \multicolumn{3}{|c|}{ HUPO } \\
\hline $\mathrm{F}$ & 5'AGCTCTGGAGAAACTGCTG3' & \multirow[t]{2}{*}{$15 \mathrm{~s}, 95^{\circ} \mathrm{C} ; 30 \mathrm{~s}, 61^{\circ} \mathrm{C} ; 30 \mathrm{~s}, 72^{\circ} \mathrm{C}$} \\
\hline $\mathrm{R}$ & 5'CAGCAGCTGGCACCTTATTG3' & \\
\hline \multicolumn{3}{|c|}{ RPL13 } \\
\hline $\mathrm{F}$ & 5'GCTCATGAGGCTACGGAAAC3' & \multirow[t]{2}{*}{$15 \mathrm{~s}, 95^{\circ} \mathrm{C} ; 30 \mathrm{~s}, 61^{\circ} \mathrm{C} ; 30 \mathrm{~s}, 72^{\circ} \mathrm{C}$} \\
\hline $\mathrm{R}$ & 5‘TATTGGGCTCAGACCAGGAG3' & \\
\hline \multicolumn{3}{|c|}{$\mathrm{ABCB} 1$} \\
\hline $\mathrm{F}$ & 5'CCCATCATTGCAATAGCAGG3' & \multirow[t]{2}{*}{$15 \mathrm{~s}, 95^{\circ} \mathrm{C} ; 30 \mathrm{~s}, 60^{\circ} \mathrm{C} ; 50 \mathrm{~s}, 72^{\circ} \mathrm{C}$} \\
\hline $\mathrm{R}$ & 5'TGTTCAAACTTCTGCTCCTGA3' & \\
\hline \multicolumn{3}{|c|}{$\mathrm{ABCC} 1$} \\
\hline $\mathrm{F}$ & 5'ATGTCACGTGGAATACCAGC3' & \multirow[t]{2}{*}{$15 \mathrm{~s}, 95^{\circ} \mathrm{C} ; 30 \mathrm{~s}, 60^{\circ} \mathrm{C} ; 50 \mathrm{~s}, 72^{\circ} \mathrm{C}$} \\
\hline $\mathrm{R}$ & 5'GAAGACTGAACTCCCTTCCT3' & \\
\hline \multicolumn{3}{|c|}{$\mathrm{ABCC} 2$} \\
\hline $\mathrm{F}$ & 5'ACAGAGGCTGGTGGCAACC3' & \multirow[t]{2}{*}{$15 \mathrm{~s}, 95^{\circ} \mathrm{C} ; 30 \mathrm{~s}, 63^{\circ} \mathrm{C} ; 30 \mathrm{~s}, 72^{\circ} \mathrm{C}$} \\
\hline $\mathrm{R}$ & 5'ACCATTACCTTGTCACTGTCCATGA3' & \\
\hline \multicolumn{3}{|c|}{$\mathrm{ABCG} 2$} \\
\hline $\mathrm{F}$ & 5'AGATGGGTTTCCAAGCGTTCAT3' & \multirow[t]{2}{*}{$15 \mathrm{~s}, 95^{\circ} \mathrm{C} ; 30 \mathrm{~s}, 57^{\circ} \mathrm{C} ; 30 \mathrm{~s}, 72^{\circ} \mathrm{C}$} \\
\hline $\mathrm{R}$ & 5'CCAGTCCCAGTACGACTGTGACA3' & \\
\hline
\end{tabular}

F, forward primer; R, reverse primer; $\beta 2$-mg, $\beta 2$-microglobulin; HPRT, hypoxanthine-phosphoribosyl transferase 1; HUPO, 60S human acidic ribosomal protein P1; RPL13, ribosomal protein L13; GU, glucuronidase- $\beta$; ABC, ATP binding cassette.

proteasome inhibitor $(\leq 100 \mu \mathrm{M})$ at $37^{\circ} \mathrm{C}$ for $10 \mathrm{~min}$. Following washing, intracellular fluorescence was analyzed using a $\mathrm{BD}^{\mathrm{TM}}$ LSR II flow cytometer with a solid state coherent sapphire blue laser and a $530 \mathrm{~nm}$ bandpass filter for 8 -FcA. In each sample, 30,000 cells were counted. The ratio between the median fluorescence of intracellular 8-FcA with and without the inhibitor was calculated in order to evaluate the inhibitor effects. The effect in the cell line HEK-293-VC G418 was used to determine whether the effects observed could be attributed to OATP inhibition. The potent OATP inhibitor rifampicin served as the positive control.

To exclude confounding variables, including leakage of the fluorescent agents due to membrane lesions, non-toxic concentrations of each of the proteasome inhibitors were determined prior to each assay using the Cytotoxicity Detection kit, according to the manufacturer's protocol. As bortezomib demonstrated $\geq 20 \%$ cytotoxicity in HEK-OATP1B3 cells at higher incubation concentrations, this compound was only examined at a concentration of $\leq 5 \mu \mathrm{M}$ in the OATP1B3 inhibition assay.

Statistical analysis. Statistical analysis was conducted using GraphPad Prism version 6.02 (GraphPad Software, Inc., La Jolla, CA, USA). Differences $>1.5$-fold threshold in mRNA-expression provoked by the proteasome inhibitors, compared with the medium control, in myeloma cells were evaluated using the Student's two-tailed t-test. Differences $>1.5$-fold threshold in mRNA-expression provoked by the proteasome inhibitors or rifampicin, compared with the medium control, in LS180 cells were analyzed using one way analysis of variance with Dunnett's post hoc test (compared with the medium control). $\mathrm{P} \leq 0.05$ was considered to indicate a statistically significant difference. 


\section{Results}

Induction of drug transporter expression. None of the proteasome inhibitors tested significantly induced or repressed any of the drug transporter genes investigated in LS180 cells (Fig. 1). As predicted, the positive control rifampicin induced the expression of typical nuclear PXR-regulated genes, including $A B C B 1$.

In the myeloma cells, only minor changes to gene expression occurred. Specifically, bortezomib did not induce the expression of any gene investigated in the present study (Fig. 2). Similarly, carfilzomib did not induce gene expression in myeloma cells, but suppressed the mRNA expression of $A B C B 1$ in LP-1 cells (Fig. 2). Ixazomib provoked certain changes in transporter gene expression, but only in a modest number of myeloma cell lines. The most pronounced effect of ixazomib was observed for $A B C G 2$, for which mRNA expression was significantly increased by 2.8 -fold in LP-1 cells, and 1.5-fold in KMM-1 and U266 cells, whereas it was significantly suppressed in Karpas-620 cells (Fig. 2). In contrast to the experiments with LS180 cells, the prototypical inducer rifampicin exhibited no significant effects on mRNA expression levels in the myeloma cells; even its typical target genes, including $A B C B 1$, were not altered upon exposure to rifampicin (data not presented).

Inhibition of drug transporter activity. Compared with carfilzomib, bortezomib and ixazomib demonstrated weak or no inhibition of the examined drug transporters. Bortezomib and ixazomib only inhibited OATP1B1, but at higher concentrations compared with carfilzomib (Table II). Apart from OATP1B1, carfilzomib also inhibited OATP1B3 with comparable potency compared with its effect on OATP1B1. Furthermore, BCRP efflux activity was inhibited with however 3-fold lower potency compared with its effect on OATP1B1. All proteasome inhibitors studied did not significantly increase intracellular calcein fluorescence at concentrations of $\geq 10 \mu \mathrm{M}$, indicating a lack of $\mathrm{P}-\mathrm{gp}$-mediated calcein-AM transport.

\section{Discussion}

Following its clinical approval in 2003, bortezomib has unquestionably revolutionized the treatment of multiple myeloma (31). Proteasome inhibitors in particular have become a primary interest of myeloma-associated research due to the significant improvements observed in the outcomes of affected patients (4). The novel proteasome inhibitors carfilzomib and ixazomib have been clinically approved and have the potential to overcome previous limitations associated with bortezomib treatment (6). To further optimize their clinical application, a review on several studies investigated the potential differences in their respective pharmacodynamic or pharmacokinetic profiles (16). However, proteasome inhibitors may also differ in their interactions with co-administered drugs (17). This may considerably alter certain factors, including the bioavailability of other chemotherapeutics that are usually part of the complex multi-drug therapy regimen for patients with myeloma (Palumbio, Mai). Therefore, the present study aimed to identify and compare such transporter-based systemic pharmacokinetic drug-drug interactions possibly mediated
Table II. Comparison of the inhibitory potential $\left(\mathrm{IC}_{50}\right)$ of bortezomib, carfilzomib and ixazomib on the activity of various drug transporters.

\begin{tabular}{lccc}
\hline & \multicolumn{3}{c}{$\mathrm{IC}_{50}, \mu \mathrm{M}$} \\
\cline { 2 - 4 } Drug transporter & Bortezomib & Carfilzomib & Ixazomib \\
\hline BCRP & N/A & $12.4 \pm 2.0$ & N/A \\
OATP1B1 & $140 \pm 9.5$ & $3.6 \pm 0.5$ & $>100$ \\
OATP1B3 & $>10^{\mathrm{a}}$ & $4.7 \pm 1.0$ & N/A \\
P-gp & N/A & N/A & N/A \\
\hline
\end{tabular}

Data are presented as the mean $\mathrm{IC}_{50} \pm$ standard deviation of $\geq 3$ transporter inhibition assays. a Cell line could not be tested at concentrations $>10 \mu \mathrm{M}$ due to relevant cytotoxic effects. N/A, no inhibition; OATP, organic anion transporting polypeptide; P-gp, P-glycoprotein; $\mathrm{BCRP}$, breast cancer resistance protein.

by bortezomib, carfilzomib or ixazomib. For experiments investigating inhibition, the focus was on the most important drug transporters for drug-drug interactions (21), whereas for experiments investigating induction, the effects on $A B C C 1$ (MRP1) and ABCC2 (MRP2) were also evaluated.

None of the tested proteasome inhibitors relevantly modified the mRNA expression of the investigated drug transporters in the LS180 induction model cell line following four days of constant exposure. This indicates that the proteasome inhibitors investigated are not activators of PXR, which usually mediates the induction of genes, including $A B C B 1, A B C C 2$ and $A B C G 2$ (32-34). This is concordant with previous in vitro studies that reported no significant changes in the expression of certain drug transporter genes ( $A B C B 1, A B C C 1$ and $A B C G 2)$, even following long-term exposure to bortezomib (35) or an increase in $A B C B 1$ expression following six months of treatment with increasing concentrations of carfilzomib only (36). As the data from the current study demonstrated that induction via PXR could be excluded, an iatrogenic increase in drug transporters, such as $A B C B 1$, may be attributed to a selection process rather than targeted transcriptional induction. Such Darwinian selection processes leading to drug resistance have previously been described for kinase inhibitors, including imatinib (37), or for classical cytotoxic compounds like docetaxel (38).

In contrast to experiments using the intestinal cell model (LS180), certain statistically significant differences in mRNA expression patterns in myeloma cells were observed following treatment with ixazomib or carfilzomib. However, the majority of the effects were statistically insignificant, and thus of debatable clinical relevance. Indeed, ixazomib significantly induced the expression of $A B C B 1$ in Karpas-620 cells, of $A B C C 1$ in L363 cells and of $A B C G 2$ in KMM-1, LP-1 and U266 cells. However, targeted induction mediated by PXR appears to improbable for the following reasons: i) These genes were not induced by ixazomib in LS180 cells (the gold-standard for PXR-mediated gene regulation); ii) the prototypical PXR ligand rifampicin had no observable significant effects in the myeloma cell lines. Thus, the mechanisms underlying the few differences in drug transporter mRNA expression 

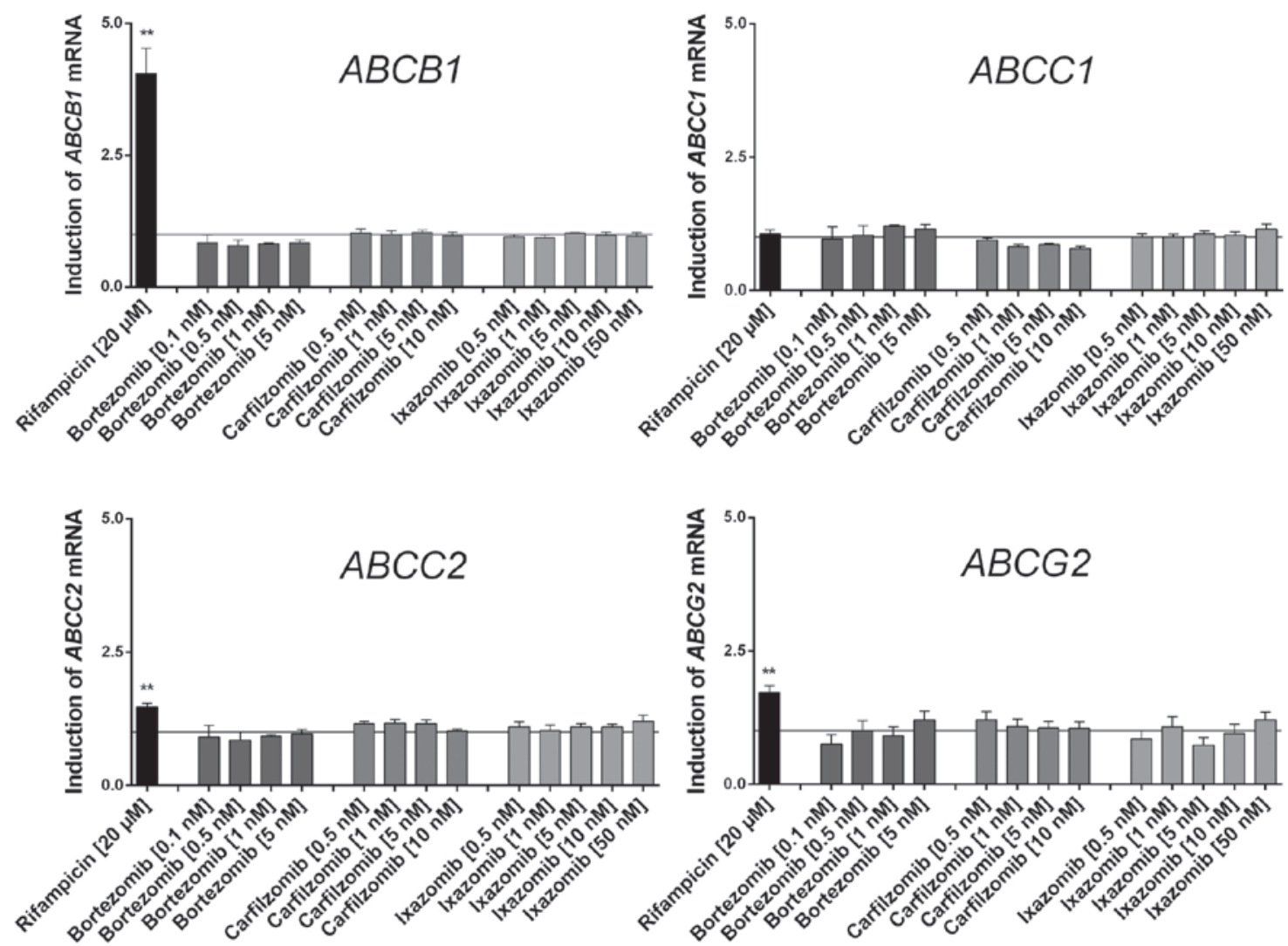

Figure 1. Effect of the proteasome inhibitors and rifampicin (positive control) on mRNA expression in LS180 cells relative to the untreated medium control following 4 days of incubation. Expression data were normalized to the respective housekeeping gene. Data are presented as the mean \pm standard error of the mean for $n=4-5$ biological replicates ( 13 for rifampicin), each of which include a technical polymerase chain reaction duplicate and are normalized to the medium control (set to 1). Discrepancies in mRNA expression, compared with the medium control, were evaluated using analysis of variance with Dunnett's post hoc test. ${ }^{*} \mathrm{P}<0.05 ;{ }^{* *} \mathrm{P}<0.01$. ABC, ATP binding cassette.
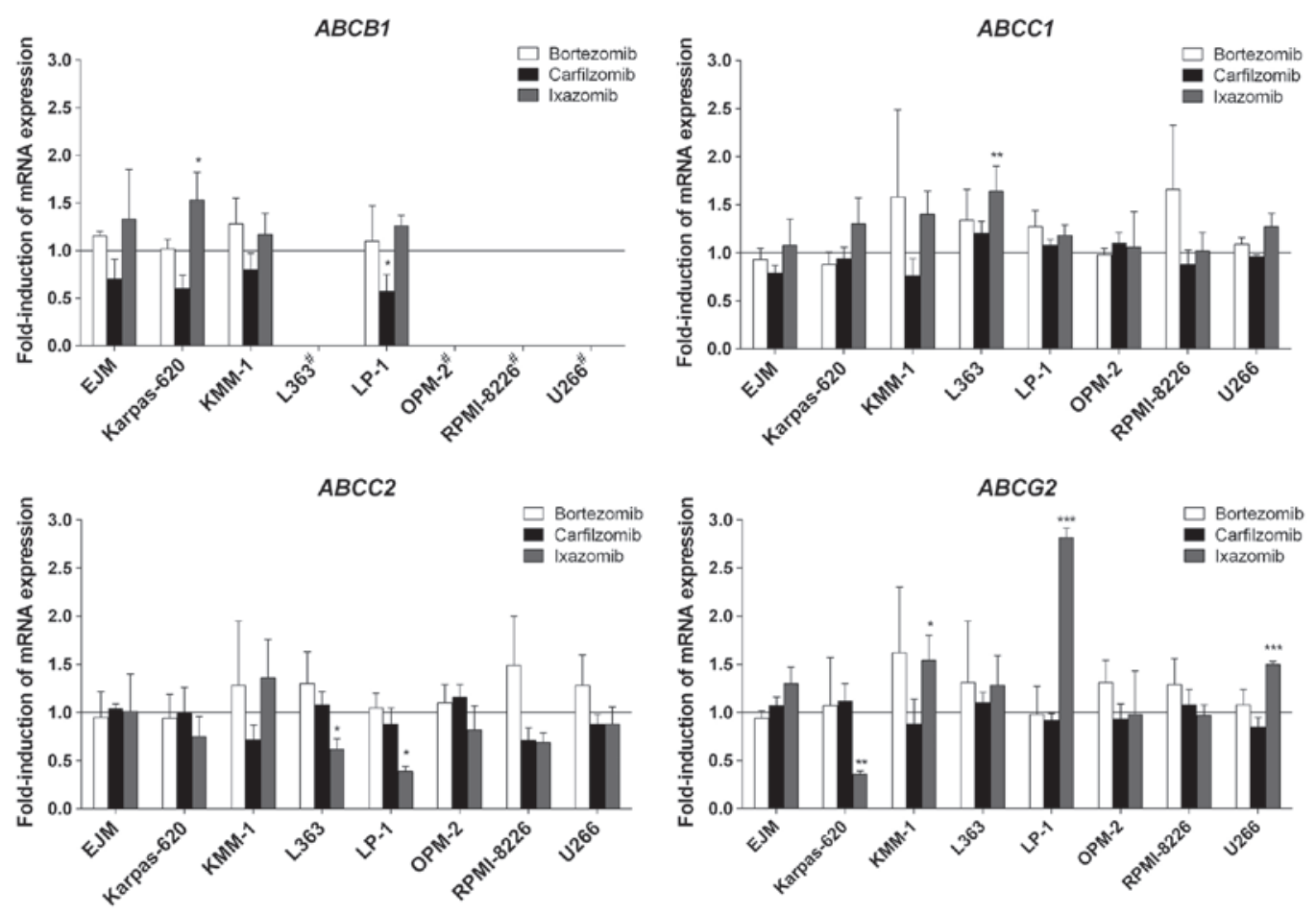

Figure 2. Effect of the proteasome inhibitors on mRNA expression in various myeloma cell lines relative to the untreated medium control following 4 days of incubation. Expression data were normalized to the respective housekeeping gene. Data are presented as the mean \pm standard error of the mean for $\mathrm{n}=4$ biological replicates, each of which include a technical polymerase chain reaction duplicate and are normalized to the medium control (set to 1). Discrepancies in mRNA expression, compared with the medium control, were investigated using the Student's t-test. ${ }^{*} \mathrm{P}<0.05 ;{ }^{* *} \mathrm{P}<0.01 ;{ }^{* * *} \mathrm{P}<0.001$; \#, mRNA expression below the lower limit of quantification $(\mathrm{Cp}>35)$. ABC, ATP binding cassette. 
observed remain uncertain. The concurrent decrease in the mRNA expression of certain genes mediated by carfilzomib and ixazomib is challenging to elucidate, but increases and decreases may have resulted from changes in mRNA stability, and not from specific transcriptional regulation.

Another principal mechanism of drug-drug interactions can be provoked by the inhibition of transporter activity (39). Bortezomib and ixazomib did not relevantly inhibit drug transporter activity. The weak inhibition of OATP1B1 effected by bortezomib only occurred at high incubation concentrations that exceeded frequently recorded plasma levels (40). Possibly, this observation results from competitive inhibition due to the weak uptake of bortezomib via OATP1B1, as previously described (10). Potentially due to structural similarities with bortezomib, the results obtained for ixazomib were predominantly comparable. In contrast to bortezomib, for which only incomplete data concerning drug transporter inhibition is available, the data for ixazomib matches the Declaration in the Summary of Product Characteristics of Ninlaro (41), indicating that ixazomib does not inhibit P-gp, BCRP, OATP1B1 and OATP1B3. By contrast with the two proteasome inhibitors containing boronic acids, carfilzomib inhibited OATP1B1 and OATP1B3 at relatively low concentrations. The data for OATP1B1 are concordant with those indicated in the Summary of Product Characteristics of Kyprolis published by the European Medicines Agency (42). Although inhibition principally occurred within the range of the maximum plasma concentrations $\left(\mathrm{C}_{\max }\right)(41)$, its relevance for clinical drug-drug interactions remains limited as carfilzomib is rapidly eliminated from the systemic circulation, leading to a rapid decline in plasma concentrations $(42,43)$. Consequently, the observed BCRP inhibition following the treatment of cells with carfilzomib appears to be less relevant. Thus far, significant drug-drug interactions have not been reported for carfilzomib in clinical trials (42). The question arises whether the effects observed in vitro are also relevant clinically. The $\mathrm{C}_{\max }$ of ixazomib are between 64-213 nM following an oral application of $4 \mathrm{mg}$ (44), distinctly exceeding the applied concentrations of $2-70 \mathrm{nM}$ in the present induction study. Therefore, the in vitro conditions utilized in this experimental set up are realistic in terms of in vivo plasma exposure. For carfilzomib, the induction concentrations in the present study were low, compared with the observable plasma peak concentrations measured in a previous study (43). However, due to high systemic clearance, carfilzomib is eliminated so rapidly from the circulation that concentrations around the $\mathrm{C}_{\max }$ are only maintained for a short period of time (45). Thus, it remains open whether changes in mRNA expression may also occur in vivo; in either case they will most likely be irrelevant to pharmacokinetic drug-drug interactions, but may contribute to the resistance of myeloma cells towards the proteasome inhibitors and other antineoplastic drugs. Together, these data indicate that no transporter-mediated systemic drug-drug interactions are to be reasonably expected in vivo.

In conclusion, the transporter-mediated systemic pharmacokinetic drug-drug interaction potential of the proteasome inhibitors bortezomib, carfilzomib and ixazomib as perpetrator drugs appears to be low. As these proteasome inhibitors did not affect the transcription of drug transporter genes in the induction model using LS180 cells, drug resistance through the iatrogenic transcriptional induction of respective transporter genes is unlikely. As proteasome inhibitors are substrates of drug transporters, Darwinian selection of pre-existing transporter overexpressing myeloma subclones may still lead to enhanced transporter expression in a given myeloma cell population.

\section{Acknowledgements}

The present study was supported by the Deutsche Forschungsgemeinschaft (grant no. SFB/TRR79) and the EU 7th Framework Program (grant no. 'OverMyR'). The authors would like to thank J. Kocher, C. Mueller, S. Rosenzweig and A. Fautsch for their technical assistance.

\section{References}

1. Adams $\mathbf{J}$ and Kauffman M: Development of the proteasome inhibitor Velcade (Bortezomib). Cancer Invest 22: 304-311, 2004.

2. Kisselev AF and Goldberg AL: Proteasome inhibitors: From research tools to drug candidates. Chem Biol 8: 739-758, 2001.

3. Richardson PG, Barlogie B, Berenson J, Singhal S, Jagannath S, Irwin D, Rajkumar SV, Srkalovic G, Alsina M, Alexanian R et al: A phase 2 study of bortezomib in relapsed, refractory myeloma. N Engl J Med 348: 2609-2617, 2003.

4. Ludwig H, Sonneveld P, Davies F, Bladé J, Boccadoro M, Cavo M, Morgan G, de la Rubia J, Delforge M, Dimopoulos M, et al: European perspective on multiple myeloma treatment strategies in 2014. Oncologist 19: 829-844, 2014.

5. Argyriou AA, Iconomou G and Kalofonos HP: Bortezomibinduced peripheral neuropathy in multiple myeloma: A comprehensive review of the literature. Blood 112: 1593-1599, 2008.

6. Dispenzieri A, Jacobus S, Vesole DH, Callandar N, Fonseca R and Greipp PR: Primary therapy with single agent bortezomib as induction, maintenance and re-induction in patients with high-risk myeloma: Results of the ECOG E2A02 trial. Leukemia 24: 1406-1411, 2010.

7. Richardson PG, Xie W, Mitsiades C, Chanan-Khan AA, Lonial S, Hassoun H, Avigan DE, Oaklander AL, Kuter DJ, Wen PY, et al: Single-agent bortezomib in previously untreated multiple myeloma: Efficacy, characterization of peripheral neuropathy, and molecular correlations with response and neuropathy. J Clin Oncol 27: 3518-3525, 2009.

8. Chen Z, Shi T, Zhang L, Zhu P, Deng M, Huang C, Hu T, Jiang L and Li J: Mammalian drug efflux transporters of the ATP binding cassette (ABC) family in multidrug resistance: A review of the past decade. Cancer Lett 370: 153-164, 2016.

9. Szakács G, Paterson JK, Ludwig JA, Booth-Genthe C and Gottesman MM: Targeting multidrug resistance in cancer. Nat Rev Drug Discov 5: 219-234, 2006.

10. Clemens J, Seckinger A, Hose D, Theile D, Longo M, Haefeli WE, Burhenne $\mathrm{J}$ and Weiss J: Cellular uptake kinetics of bortezomib in relation to efficacy in myeloma cells and the influence of drug transporters. Cancer Chemother Pharmacol 75: 281-291, 2015.

11. Siegel DS, Martin T, Wang M, Vij R, Jakubowiak AJ, Lonial S, Trudel S, Kukreti V, Bahlis N, Alsina M et al: A phase 2 study of single-agent carfilzomib (PX-171-003-A1) in patients with relapsed and refractory multiple myeloma. Blood 120: 2817-2825, 2012.

12. Demo SD, Kirk CJ, Aujay MA, Buchholz TJ, Dajee M, Ho MN, Jiang J, Laidig GJ, Lewis ER, Parlati F, et al: Antitumor activity of PR-171, a novel irreversible inhibitor of the proteasome. Cancer Res 67: 6383-6391, 2007.

13. Kuhn DJ, Chen Q, Voorhees PM, Strader JS, Shenk KD, Sun CM, Demo SD, Bennett MK, van Leeuwen FW, Chanan-Khan AA, et al: Potent activity of carfilzomib, a novel, irreversible inhibitor of the ubiquitin-proteasome pathway, against preclinical models of multiple myeloma. Blood 110: 3281-3290, 2007.

14. Gentile M, Offidani M, Vigna E, Corvatta L, Recchia AG, Morabito L, Morabito F and Gentilli S: Ixazomib for the treatment of multiple myeloma. Expert Opin Investig Drugs 24: 1287-1298, 2015.

15. Ocio EM, Mitsiades CS, Orlowski RZ and Anderson KC: Future agents and treatment directions in multiple myeloma. Expert Rev Hematol 7: 127-141, 2014 
16. Teicher BA and Tomaszewski JE: Proteasome inhibitors. Biochem Pharmacol 96: 1-9, 2015.

17. Palumbo A, Bringhen S, Rossi D, Cavalli M, Larocca A, Ria R, Offidani M, Patriarca F, Nozzoli C, Guglielmelli T, et al: Bortezomib-melphalan-prednisone-thalidomide followed by maintenance with bortezomib-thalidomide compared with bortezomib-melphalan-prednisone for initial treatment of multiple myeloma: A randomized controlled trial. J Clin Oncol 28 : 5101-5109, 2010.

18. Mai EK, Bertsch U, Dürig J, Kunz C, Haenel M, Blau IW, Munder M, Jauch A, Schurich B, Hielscher T, et al: Phase III trial of bortezomib, cyclophosphamide and dexamethasone (VCD) versus bortezomib, doxorubicin and dexamethasone (PAd) in newly diagnosed myeloma. Leukemia 29: 1721-1729, 2015.

19. Aras B and Yerlikaya A: Bortezomib and etoposide combinations exert synergistic effects on the human prostate cancer cell line PC-3. Oncol Lett 11: 3179-3184, 2016.

20. Yerlikaya A, Erdoğan E, Okur E, Yerlikaya S and Savran B: A novel combination treatment for breast cancer cells involving BAPTA-AM and proteasome inhibitor bortezomib. Oncol Lett 12: 323-330, 2016.

21. Müller F and Fromm MF: Transporter-mediated drug-drug interactions. Pharmacogenomics 12: 1017-1037, 2011

22. Weiss J, Theile D, Spalwisz A, Burhenne J, Riedel KD and Haefeli WE: Influence of sildenafil and tadalafil on the enzymeand transporter-inducing effects of bosentan and ambrisentan in LS180 cells. Biochem Pharmacol 85: 265-273, 2013.

23. Gupta A, Mugundu GM, Desai PB, Thummel KE and Unadkat JD: Intestinal human colon adenocarcinoma cell line LS180 is an excellent model to study pregnane $\mathrm{X}$ receptor; but not constitutive androstane receptor; mediated CYP3A4 and multidrug resistance transporter 1 induction: Studies with anti-human immunodeficiency virus protease inhibitors. Drug Metab Dispos 36: 1172-1180, 2008.

24. Harper PA, Prokipcak RD, Bush LE, Golas CL and Okey AB: Detection and characterization of the Ah receptor for 2;3;7;8-tetrachlorodibenzo-p-dioxin in the human colon adenocarcinoma cell line LS180. Arch Biochem Biophys 290: 27-36, 1991.

25. König J, Cui Y, Nies AT and Keppler D: Localization and genomic organization of a new hepatocellular organic anion transporting polypeptide. J Biol Chem 275: 23161-23168, 2000.

26. König J, Cui Y, Nies AT and Keppler D: A novel human organic anion transporting polypeptide localized to the basolateral hepatocyte membrane. Am J Physiol Gastrointest Liver Physiol 278: G156-G164, 2000.

27. Pavek P, Merino G, Wagenaar E, Bolscher E, Novotna M, Jonker JW and Schinkel AH: Human breast cancer resistance protein: Interactions with steroid drugs, hormones, the dietary carcinogen 2-amino-1-methyl-6-phenylimidazo(4,5-b)pyridine, and transport of cimetidine. J Pharmacol Exp Ther 312: 144-152, 2005.

28. Boesch D, Gavériaux C, Jachez B, Pourtier-Manzanedo A, Bollinger $P$ and Loor $F$ : In vivo circumvention of P-glycoprotein-mediated multidrug resistance of tumor cells with SDZ PSC 833. Cancer Res 51: 4226-4233, 1991.

29. Peters T, Lindenmaier H, Haefeli WE and Weiss J: Interaction of the mitotic kinesin Eg5 inhibitor monastrol with P-glycoprotein. Naunyn Schmiedebergs Arch Pharmacol 372: 291-299, 2006.
30. Vandesompele J, De Preter K, Pattyn F, Poppe B, Van Roy N, De Paepe A and Speleman F: Accurate normalization of real-time quantitative RT-PCR data by geometric averaging of multiple internal control genes. Genome Biol 3: RESEARCH0034, 2002.

31. Fröhlich M, Albermann N, Sauer A, Walter-Sack I, Haefeli WE and Weiss J: In vitro and ex vivo evidence for modulation of P-glycoprotein activity by progestins. Biochem Pharmacol 68: 2409-2416, 2004

32. Weiss J, Rose J, Storch CH, Ketabi-Kiyanvash N, Sauer A, Haefeli WE and Efferth T: Modulation of human BCRP (ABCG2) activity by anti-HIV drugs. J Antimicrob Chemother 59: 238-245, 2007.

33. Moreau P, Richardson PG, Cavo M, Orlowski RZ, San Miguel JF, Palumbo A and Harousseau JL: Proteasome inhibitors in multiple myeloma: 10 years later. Blood 120: 947-959, 2012.

34. Geick A, Eichelbaum M and Burk O: Nuclear receptor response elements mediate induction of intestinal MDR1 by rifampin. J Biol Chem 276: 14581-14587, 2001.

35. Oerlemans R, Franke NE, Assaraf YG, Cloos J, van Zantwijk I, Berkers CR, Scheffer GL, Debipersad K, Vojtekova K, Lemos C et al: Molecular basis of bortezomib resistance: Proteasome subunit beta5 (PSMB5) gene mutation and overexpression of PSMB5 protein. Blood 112: 2489-2499, 2008

36. Ao L, Wu Y, Kim D, Jang ER, Kim K, Lee DM, Kim KB and Lee W: Development of peptide-based reversing agents for p-glycoprotein-mediated resistance to carfilzomib. Mol Pharm 9: 2197-2205, 2012

37. Blagosklonny MV: STI-571 must select for drug-resistant cells but 'no cell breathes fire out of its nostrils like a dragon'. Leukemia 16: 570-572, 2002.

38. De Souza R, Zahedi P, Badame RM, Allen C and Piquette-Miller M: Chemotherapy dosing schedule influences drug resistance development in ovarian cancer. Mol Cancer Ther 10: 1289-1299, 2011

39. Yu DK: The contribution of P-glycoprotein to pharmacokinetic drug-drug interactions. J Clin Pharmacol 39: 1203-1211, 1999.

40. Moreau P, Karamanesht II, Domnikova N, Kyselyova MY, Vilchevska KV, Doronin VA, Schmidt A, Hulin C, Leleu X, Esseltine DL, et al: Pharmacokinetic, pharmacodynamic, and covariate analysis of subcutaneous versus intravenous administration of bortezomib in patients with relapsed multiple myeloma. Clin Pharmacokinet 51: 823-829, 2012.

41. Summary of product characteristics for Ninlaro: www.accessdata.fda.gov/drugsatfda_docs/label/.../208462lbl.pdf

42. Summary of product characteristics for Kyprolis: ec.europa. eu/health/documents/...register/.../anx_133351_en.pdf

43. Wang Z, Yang J, Kirk C, Fang Y, Alsina M, Badros A, Papadopoulos K, Wong A, Woo T, Bomba D, et al: Clinical pharmacokinetics, metabolism, and drug-drug interaction of carfilzomib. Drug Metab Dispos 41: 230-237, 2013.

44. Richardson PG, Baz R, Wang M, Jakubowiak AJ, Laubach JP, Harvey RD, Talpaz M, Berg D, Liu G, Yu J, et al: Phase 1 study of twice-weekly ixazomib, an oral proteasome inhibitor, in relapsed/refractory multiple myeloma patients. Blood 124: 1038-1046, 2014

45. Thompson JL: Carfilzomib: A second-generation proteasome inhibitor for the treatment of relapsed and refractory multiple myeloma. Ann Pharmacother 47: 56-62, 2013. 